\title{
KEANEKARAGAMAN JENIS KUPU-KUPU PADA LIMA TIPE HUTAN DI AREAL PT. HUTAN KETAPANG INDUSTRI KALIMANTAN BARAT
}

\author{
(Diversity of Butterfly in five Forest Types in The PT.Hutan Ketapang Industri \\ West Kalimantan)
}

\author{
Jogi Yoepi Sinaga, Slamet Rifanjani, Ahmad Yani \\ Fakultas Kehutanan Universitas Tanjungpura Jl. Daya Nasional, Pontianak 78124 \\ E-mail : jogisinaga62@gmail.com
}

\begin{abstract}
Butterflies are species of insect found in all types of habitats. Butterflies can be used as bioindicators of environmental change because butterflies are very sensitive to biotic and abiotic factors. The aim of this study to obtain data the diversity of butterfly species in several habitat types in the PT.Hutan Ketapang Industri. This study used observation method with a sweeping that is using insect nets and researchers are free to explore the area randomly for a specified time. This research was conducted in 5 Habitats, kerangas forest, peat swamp, lowland dipterocarps, riparian and wetlands. Five forest types are selected based on the density and diversity of forest vegetation. The results found 14 species with a total of 316 individuals. Based on the calculation of species diversity index of butterflies in five locations of 2.54212, shows that the diversity is classified as moderate and has an abundance index value of 0.963289 indicates that the abundance is classified as high. Then obtained a value of species wealth index of 2.75651 is classified as moderate and has a value of dominance index of 0.0868651 indicates that there is no dominant type
\end{abstract}

Keywords: butterfly, diversity, habitat, bioindicator

\section{PENDAHULUAN}

Kupu-kupu merupakan salah satu jenis serangga dari ordo Lepidoptera, memiliki keindahan warna dan bentuk sayap. Kupu-kupu di alam memiliki peran penting dalam keseimbangan ekosistem yaitu, sebagai penyerbuk pada proses pembuahan tanaman. Kupu-kupu adalah salah satu jenis serangga dalam daftar kekayaan hayati Indonesia dan kupu-kupu termasuk kedalam ordo Lepidoptera (Braby, 2004). Kelompok serangga ini cukup dikenal karena dapat ditemukan hampir di setiap tempat dan dapat dibedakan dengan serangga lain karena, kupu-kupu memiliki warna mencolok dan pola pada sayap beranekaragam. Berdasarkan karakteristik ini, kupukupu dikelompokkan dalam beberapa famili, diantaranya Papilionidae, Pieridae, Nymphalidae, Lycaenidae, Hesperiidae, dan Riodae.

Indonesia merupakan salah satu negara dengan kawasan hutan hujan tropis yang kaya akan keanerakagaman flora dan faunanya termasuk kupukupu. Keadaan alam dengan iklim tropis menjadikan kawasan tersebut menjadi habitat yang cocok bagi perkembangan berbagai spesies kupu-kupu. Salah satunya pada hutan Kalimantan yang memiliki keanekaragaman hayati dan endemisitas yang tinggi (Meijaard dan 
Nijman 2003). Serangga unik ini dapat dijadikan indikator perubahan lingkungan karena, sifatnya yang rentan terhadap adanya gangguan. Perubahan habitat kupu-kupu dapat menyebabkan terjadinya perubahan komposisi spesies (Rossi dan Halder, 2009) dan dapat mempengaruhi kelimpahan kupu-kupu (Jonason, et al., 2009).

PT. Hutan Ketapang Industri adalah sebuah perusahaan yang beroperasi di Kecamatan Kendawangan, Kabupaten Ketapang Provinsi Kalimantan Barat. Kawasanya memiliki beberapa tipe ekosistem yakni hutan kerangas, hutan rawa gambut, hutan dipterocarps atau dataran rendah, riparian dan lahan basah terbuka atau dataran banjir. Kondisi ini menyebabkan jenis kupu-kupu jumlahnya lebih beragam Oleh karena itu, penelitian ini bertujuan untuk mendapatkan data keanekaragaman jenis kupu-kupu di beberapa tipe habitat di Areal PT. Hutan Ketapang Industri Kabupaten Ketapang.

\section{METODE PENELITIAN}

Penelitian dilaksanakan di Areal Hutan PT. Hutan Ketapang Industri Kecamatan Kendawangan Kabupaten Ketapang dengan waktu 3 Minggu, dari tanggal 21 Februari - 14 Maret 2019 di PT.Hutan Ketapang Industi, meliputi hutan kerangas, hutan rawa gambut, hutan dipterocarps, hutan riparian dan hutan lahan basah terbuka atau dataran banjir.

Alat-alat yang digunakan antara lain adalah kamera, jaring serangga, peta lokasi, buku identifikasi, jarum suntik, kertas papilot, kotak spesimen dan tally sheet. Bahan yang digunakan adalah alkohol $70 \%$ untuk mengawetkan kupu-kupu. Metode penelitian menggunakan metode observasi lapangan dengan teknik sweeping net (Coote, 2000) dan jelajah. Penangkapan kupu-kupu juga menggunakan food trap untuk mengantisipasi kupu-kupu yang susah ditangkap. Food trap terbuat dari madu dan buah nanas yang busuk. Kupu-kupu yang tertangkap disuntik dan dimasukkan ke dalam kertas papilot untuk dibuat insectarium, kemudian kupu-kupu diidentifikasi berdasarkan literatur dari Peggie dan Amir (2006), Peggie (2011), Kunci determinasi Serangga (1991) dan Kupu-kupu Lampung (2016).

\section{Analisis data}

Indeks keanekaragaman jenis (H') Keanekaragaman jenis kupu-kupu dapat dihitung menggunakan indeks keanekaragaman Shannon-Wiener (Odum, 1996), Indeks kelimpahan jenis (e) Kelimpahan Pielou (Odum, 1996), Indeks kekayaan jenis merupakan jumlah jenis dalam suatu luasan areal tertentu. Indeks yang digunakan adalah indeks kekayaan Margalef dengan persamaan (Shannon-Wiener dengan rumus Odum,1996), Indeks dominansi (C) digunakan untuk menentukan atau menetapkan jenis kupu-kupu yang dominan, dominan sedang atau tidak dominan dalam suatu jalur pengamatan. Rumus yang digunakan menurut Odum (1996) menggunakan indeks dominansi Simpson (D), Indeks kesamaan jenis (IS) merupakan nilai yang menunjukan 
tingkat kesamaan jenis penyusunan populasi satwa tertentu yang diperoleh dengan membandingkan 2 komunitas tertentu rumus menurut Shannon-wiener (Odum 1996).

\section{HASIL DAN PEMBAHASAN}

Hasil pengamatan jumlah total jenis kupu-kupu yang ditemukan pada Areal
PT. Hutan Ketapang Industri sebanyak 14 jenis dengan jumlah individu sebanyak 316 individu. Kupu-kupu yang ditemukan termasuk kedalam family Nympalidae, Papilionidae, Lycanidae, Pieridae.

Tabel 1. Jumlah jenis kupu-kupu pada PT. Hutan Ketapang Industri (The number of species of butterfly in PT. ketapang forest industry)

\begin{tabular}{|c|c|c|c|c|c|c|c|}
\hline No & Famili & $\begin{array}{c}\text { Jenis } \\
\text { kupu -kupu }\end{array}$ & $\begin{array}{l}\text { lah } \\
\text { carps }\end{array}$ & $\begin{array}{c}\text { Jumlah } \\
\text { Rawa } \\
\text { Gambut }\end{array}$ & $\begin{array}{l}\text { Jumlah } \\
\text { Lahan } \\
\text { Basah }\end{array}$ & $\begin{array}{l}\text { Jumlah } \\
\text { Riparian }\end{array}$ & $\begin{array}{c}\text { Jumlah } \\
\text { Kerangas }\end{array}$ \\
\hline \multirow[t]{7}{*}{1} & Nymphalidae & $\begin{array}{l}\text { Mycalesis sirius } \\
\text { canicula }\end{array}$ & 3 & 2 & 3 & 5 & \\
\hline & & Melanitis leda & 11 & 13 & 8 & 8 & 9 \\
\hline & & Neptis hylas & 4 & 4 & 4 & 3 & 4 \\
\hline & & Phaedyma columella & 6 & 6 & 5 & 6 & - \\
\hline & & Euploea mulciber & 3 & 3 & 3 & 1 & \\
\hline & & Mycalesis persus & 4 & 5 & 3 & 5 & 9 \\
\hline & & Acracea violae & 4 & 9 & 4 & 5 & - \\
\hline \multirow[t]{3}{*}{2} & Pieridae & Leptosia nina & 7 & 5 & 4 & 3 & 4 \\
\hline & & Eurema sari & 21 & 5 & 6 & 9 & - \\
\hline & & Eurema blanda & 6 & 4 & 5 & 6 & - \\
\hline \multirow[t]{3}{*}{3} & Papilionidae & $\begin{array}{l}\text { Graphium } \\
\text { agmemnon }\end{array}$ & 4 & 3 & 3 & 2 & - \\
\hline & & Papilio polytes & 3 & 5 & 3 & 4 & 2 \\
\hline & & Graphium sarpedon & 4 & 4 & 3 & 3 & - \\
\hline \multirow[t]{3}{*}{4} & Lycanidae & Jamides pura & 5 & 6 & 5 & 5 & 4 \\
\hline & Jumlah indiv & vidu & 86 & 74 & 60 & 64 & 32 \\
\hline & Jumlah spesi & & 14 & 14 & 14 & 14 & 6 \\
\hline
\end{tabular}


Berdasarkan Tabel 1 Eurema sari merupakan kupu-kupu yang paling banyak ditemui pada 5 tipe hutan. Banyak ditemukannya kupu-kupu jenis ini selain dikarenakan kondisi habitat yang sesuai juga ada faktor lain seperti kondisi lingkungan yang relatif masih terjaga sehingga predator sulit menemukannya. Kupu-kupu ini mempunyai daya tahan tubuh yang cukup kuat sehingga pada saat hujan ringan ataupun mendung kupu-kupu ini dapat terbang dan kebiasaannya jarang sekali hinggap di dedaunan. Kupu-kupu jenis Phaedyma columella ditemukan pada 4 tipe hutan yaitu, hutan rawa gambut, hutan dipterocarps, hutan riparian, hutan lahan basah terbuka, sedangkan di hutan kerangas tidak ditemukan jenis tersebut. Hal tersebut diduga berkaitan dengan kondisi vegetasi yang berbeda. Banyaknya tempat yang terbuka karena adanya aktifitas manusia yaitu pembalakan liar (illegal loging) sehingga rusaknya habitat yang berdampak pada keberadaan jenis kupu-kupu, kerusakan habitat ini mengakibatkan beberapa jenis tumbuhan sebagai sumber pakan bagi kupu-kupu juga ikut rusak, sehingga kupu-kupu agak sulit ditemukan di hutan kerangas.

Tabel 2. Hasil Analisis indeks keanekaragaman, kelimpahan, kekayaan dan dominasi jenis kupu-kupu. (the analysis of butterfly diversity, abdudance, richness and dominance)

\begin{tabular}{lcccccc}
\hline \multicolumn{1}{c}{ Lokasi } & $\begin{array}{c}\text { Jumlah } \\
\text { jenis }\end{array}$ & $\begin{array}{c}\text { Jumlah } \\
\text { individu }\end{array}$ & H' & e & Dmg & C \\
\hline Dipterocarps & 14 & 86 & 2,43 & 0,92 & 2,91 & 0,11 \\
$\begin{array}{l}\text { Rawa } \\
\text { Gambut }\end{array}$ & 14 & 74 & 2,52 & 0,95 & 3,02 & 0,08 \\
$\begin{array}{l}\text { Riparian } \\
\text { Lahan }\end{array}$ & 14 & 64 & 2,52 & 0,95 & 3,12 & 0,08 \\
Basah & 14 & 60 & 2,59 & 0,98 & 3,17 & 0,08 \\
Kerangas & 6 & 32 & 1,66 & 0,93 & 1,44 & 0,50 \\
\hline Total & 32 & 316 & 2,54 & 0,96 & 2,75 & 0,08 \\
\hline
\end{tabular}


Berdasarkan indeks keanekaragaman Shannon-Wiener (H') yang terdapat pada tabel 2, keanekaragaman jenis kupu-kupu dan kelimpahan jenis kupu-kupu, pada tiap lokasi meliputi antara lain: Hutan Dipterocarps, Rawa Gambut, Riparian, Lahan Basah, Kerangas, menunjukan keanekaragaman jenis tersebut termasuk kedalam kategori sedang, memiliki nilai $\left(H^{\prime}\right)=2,54$ dan kelimpahan jenis kupukupu tersebut termasuk kedalam kategori tinggi, memiliki nilai $(\mathrm{E})=0,96$, karena kriteria menurut Odum (1996) bahwa nilai e $\geq 0,6$ tergolong tinggi, selain itu keadaan lingkungan seperti keterbukaan tempat, keragaman vegetasi dan kerapatan vegetasi memberikan pengaruh pada jenis kupu-kupu pada suatu habitat. Keberadaan jenis kupu-kupu juga dipengaruhi oleh makanan yang tersedia di lokasi penelitian.

Hutan Lahan Basah memiliki nilai kekayaan jenis (Dmg) tertinggi yaitu 3,17. Kriteria menurut Jorgensen et al. (2005) karena rentang nilai 2,5-4,0 tergolong sedang maka. Nilai tersebut termasuk kedalam kategori sedang, dibandingkan dengan Hutan Kerangas memiliki nilai kekayaan jenis buruk yaitu 1,44. Hutan Lahan Basah menunjukkan nilai yang lebih tinggi dibandingkan Hutan Kerangas. Hal ini disebabkan karena pada Hutan Lahan Basah memiliki tingkat keanekaragaman hayati yang tinggi dan memiliki lahan basah yang kaya akan kandungan air. Sehingga habitat hutan lahan basah sangat disukai oleh kupu-kupu dan memiliki nilai kekayaan keanekaragaman hayati yang tinggi. Sedangkan pada Hutan Kerangas memiliki kondisi hutan pasca terbakar, memiliki lahan dan suhu ekstream, dan rawan atau sangat peka terhadap gangguan seperti kebakaran hutan, longsor, dan banjir. Sehingga nilai keanekaragaman jenis kupu-kupu pada Hutan Kerangas rendah. Kriteria menurut Jorgensen et al. (2005) karena rentang nilai $<2,5$ tergolong buruk. Menunjukan adanya pengaruh karakteristik dari habitat yang berbeda terhadap pola sebaran kupu-kupu yang ada pada areal PT Hutan Ketapang Industri.

Tabel 3. Hasil analisis indeks kesamaan jenis Sorensen (Results of Sorensen type Similarity index analysis)

\begin{tabular}{lcc}
\hline Habitat & $\begin{array}{c}\text { Jumlah jenis } \\
\text { yang sama }\end{array}$ & IS \\
\hline Dipterocarps-Rawa Gambut & 14 & $100 \%$ \\
Dipterocarps-Lahan Basah & 14 & $100 \%$ \\
Dipterocarps-Riparian & 14 & $100 \%$ \\
Dipterocarps-Kerangas & 6 & $60 \%$ \\
Rawa Gambut-Lahan Basah & 14 & $100 \%$ \\
Rawa Gambut-Riparian & 14 & $100 \%$ \\
Rawa Gambut-Kerangas & 6 & $100 \%$ \\
Lahan Basah-Riparian & 14 & $60 \%$ \\
Lahan Basah-Kerangas & 6 & $60 \%$ \\
Riparian-Kerangas & 6 & $60 \%$ \\
\hline
\end{tabular}


Berdasarkan analisis indeks kesamaan jenis hanya empat habitat yang memiliki nilai kesamaan jenis yang sama karena vegetasi hutan tersebut memiliki tingkat keanekaragaman hayati tinggi dan kupukupu banyak ditemukan di habitat tersebut seperti Hutan Dipterocarps, Rawa Gambut, Riparian, Lahan Basah, dengan nilai indeks kesamaan jenis sebesar $100 \%$, dan ditemukan 14 jenis kupu-kupu yang sama yaitu Mycalesis Sirius canicula, Melanitis leda, Neptis hylas, Phaedyma columella, Euploea mulciber, Mycalesis persus, Acracea violae, Leptosia nina, Eurema sari, Eurema blanda, Graphium agmemnon, Papilio polytes, Graphium sarpedon dan Jamides pura. Nilai indeks dibandingkan dengan hutan kerangas, lokasi yang lain pada saat dibandingkan dengan lokasi hutan kerangas memiliki nilai indeks kesamaan (IS) sebesar 60\%, artinya masih ada perbedaan jenis antara habitat tersebut dan hal ini disebabkan karena pada Hutan Kerangas memiliki kondisi hutan pasca terbakar dan memiliki suhu ekstream, dan rawan atau sangat peka terhadap ganguan seperti kebakaran dan longsor sehingga sedikit ditemukan jenis kupu-kupu di hutan kerangas tersebut dan hanya 6 jenis kupu-kupu yang sama dengan tipe hutan yang lain, yaitu Mysalesius persus, Neptis hylas, Papilio polytes, Leptosia nina, Jamides pura dan Melanitis leda. kesamaan sedikit berbeda jika

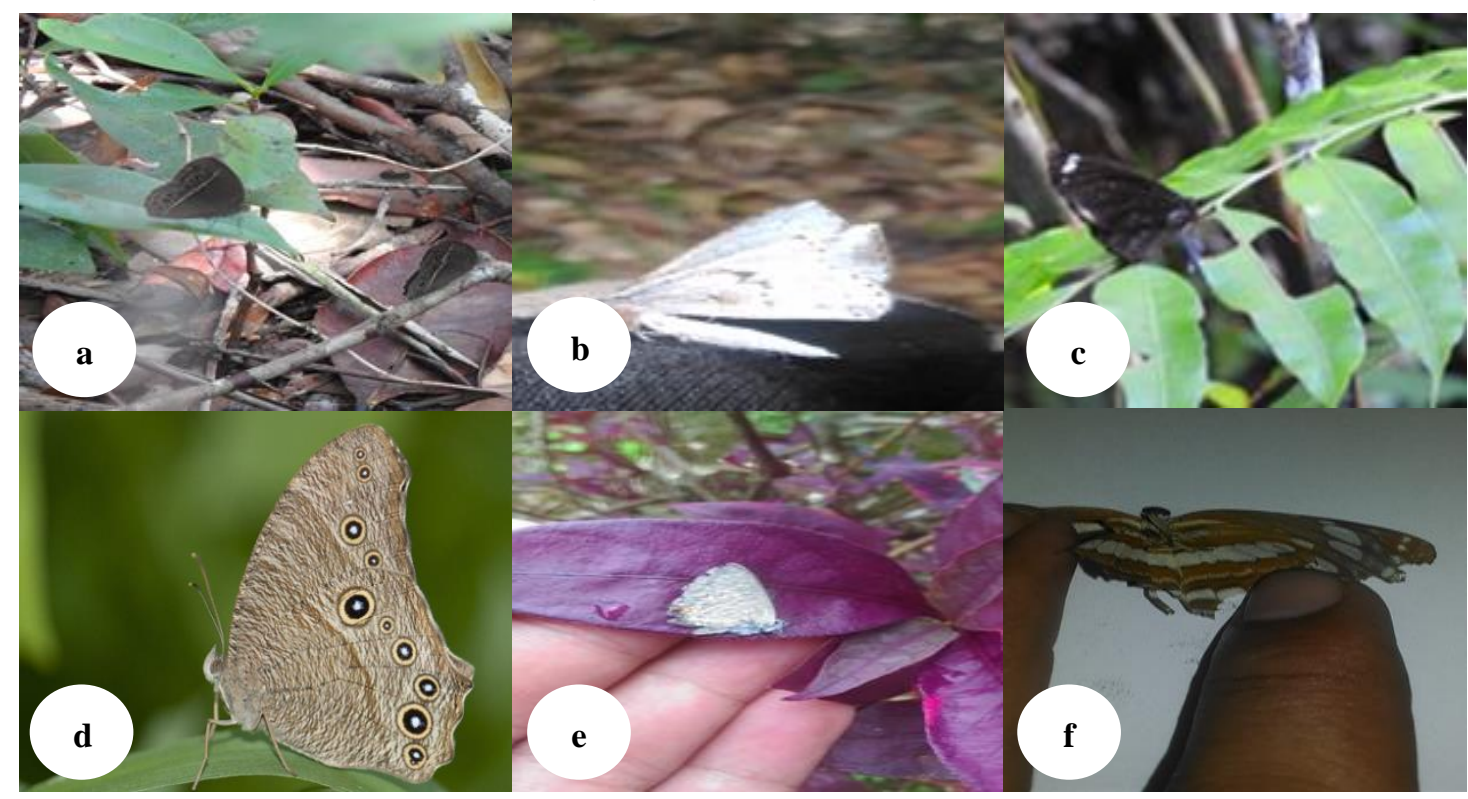

Gambar 1. Jenis kupu-kupu yang ditemukan disemua habitat penelitian yaitu, a). Mysalesius persus, b). Leptosia nina, c).Papilio polytes, d). Melanitis leda e). Jamides pura dan f). Neptis hylas.

Family Nymphalidae merupakan family yang paling banyak dijumpai di lokasi penelitian, sedangkan family Lycanidae paling sedikit dijumpai.
Adanya kesamaan jenis kupu-kupu pada lima lokasi penelitian disebabkan oleh berberapa kesamaan vegetasi ataupun kesamaan pakan kupu-kupu 


\section{KESIMPULAN}

Wilayah Konservasi PT. Hutan Ketapang Industri yang terdiri dari kawasan Hutan Dipterocarps, Hutan Lahan Basah, Hutan Rawa Gambut, Hutan Riparian dan Hutan Kerangas terdapat 14 jenis kupu-kupu di seluruh habitat yang merupakan anggota dari 4 famili dengan jumlah individu 316 yaitu Nymphalidae (7), Papilionidae (3), Pieridae (3), dan Lycaenidae (1). Famili yang paling banyak di temui adalah Nymphalidae. Nilai indeks keanekaragamannya sebesar 2,54, nilai indeks kelimpahannya sebesar 0,96, nilai indeks kekayaan jenis sebesar 2,75 , nilai indeks dominansi yaitu 0,08 yang menunjukkan bahwa tidak terdapat jenis yang mendominasi. Hasil menunjukan bahwa wilayah konservasi PT.HKI menjadi habitat yang potensial untuk jenis kupu-kupu di Kalimantan Barat.

\section{SARAN}

Berdasarkan penelitian yang telah dilakukan dan kesimpulan di atas, maka saran yang dapat diberikan guna untuk penelitian selanjutnya adalah perlu dilakukan penangkaran untuk jenis kupu-kupu tertentu yang jumlahnya jarang ditemukan dengan membuat budidaya atau penangkaran guna untuk kelestarian konservasi keanekaragaman hayati secara utuh.

\section{UCAPAN TERIMAKASIH}

Terimakasih penulis ucapkan kepada PT. HKI (Hutan Ketapang Industri), yang telah memberikan peluang dan bantuan banyak dalam penelitian serta memberikan materi dan tempat dalam penelitian sehingga penulis dapat menyelesaikan perkuliahan sarjana kehutanan.

\section{DAFTAR PUSTAKA}

Braby MF. 2004. The Complete Field Guide to Butterflies of Australia. Csiro Publishing. Australia.

Coote LD. 2000. CITES Identification Guide Butterflies. Minister of Environment.Canada.

Jonason D, Milberg dan Bergman KO. 2009. Monitoring of butterflies within a landscape context in south Eastern Sweden. J for Nat Cons. 189 (1): 22-23.

Margareta F, Tri R S. , Ari H Y. 2015. Inventarisasi Jenis Kupu-kupu pada Hutan Kerangas di Kawasan Cagar Alam Mandor Kabupaten Landak. Jurnal Protobiont (2015) Vol. 4 (1) : 260-265.

Meijaard, M. dan V. Nijman.2003. Primate hotspots on Borneo: predictive value for general biodiversity and the effects of taxonomy. Conservation Biology 17: $725-732$.

Odum EP. 1996. Dasar-dasar Ekologi. Edisi ke-3. Terjemahan Tjahjono Samingan. Gadjah Mada University Press. Yogyakarta.

Peggie D. 2011. Precious and Protected Indonesian Butterflies. Jakarta: Puslitbang Biologi LIPI and Nagao NEF.

Peggie, D., dan Amir, M.,2006. Practical Guide to the Butterflies of Bogor Botanical Garden, Panduan Praktis Kupu-kupu di Kebun Raya Bogor. Bogor: Pusat Penelitian dan Pengembangan Biologi Lembaga Ilmu Pengetahuan Indonesia. 
JURNAL HUTAN LESTARI (2019)

Vol. 7 (3) : 1313 - 1320

Rizal S. 2007. Populasi Kupu-kupu Kawasan Cagar Alam Rimbo Panti dan Kawasan Wisata Lubuk Minturun Sumatera Barat. Mandiri 9 (3): 177-237.

Rossi JP dan Halder IV. 2009. Towards indicators of butterfly biodiversity based on a Multiscale landscape description. Eco Indicators. $10: 452-458$ 